\title{
Sensory and Motor Characterization in the Postnatal Valproate Rat Model of Autism
}

\author{
Stacey Reynolds ${ }^{a} \quad$ Alexandre Millette $^{b}$ Darragh P. Devine ${ }^{c}$ \\ ${ }^{a}$ Department of Occupational Therapy, Virginia Commonwealth University, Richmond, Va., and Departments

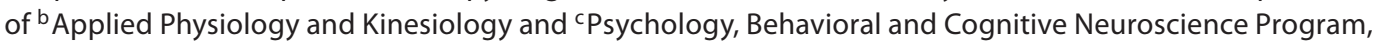 \\ University of Florida, Gainesville, Fla., USA
}

\section{Key Words}

Valproate rat model · Autism spectrum disorders · Sensory and motor performance

\begin{abstract}
Although autism is diagnosed according to three core features of social deficits, communication impairments, and repetitive or stereotyped behaviors, other behavioral features such as sensory and motor impairments are present in more than $70 \%$ of individuals with autism spectrum disorders (ASD). Exposure of rat pups to the teratogen valproate during sensitive periods of brain development has been shown to elicit behavioral features associated with autism diagnosis and has been proposed as a valid animal model of the disorder. The purpose of this study was to characterize sensory and motor performance in rats postnatally treated with valproate. Thirty-four rat pups were injected with either valproate $(150 \mathrm{mg} / \mathrm{kg})$ or saline on postnatal days 6-12. Auditory and tactile startle as well as auditory sensory gating was assessed during both the juvenile and adolescent stages of development; motor testing was conducted during late adolescence and included a sunflower seed eating task and a vermicelli handling task. Valproate-treated rats were under-
\end{abstract}

responsive to auditory stimuli, showed deficits in auditory sensory gating, and demonstrated impairments in motor speed and performance. These findings suggest that postnatal valproate treatment elicits sensory and motor features often seen in individuals with ASD. Further, the hyposensitivity seen in postnatally valproate-treated rats contrasted with hypersensitivity previously reported in prenatally valproateexposed rats. This suggests that timing of teratogenic exposure during early brain development may be important to consider when investigating the neurobiological basis of sensorimotor impairments in ASD.

Copyright $\odot 2012$ S. Karger AG, Basel

\section{Introduction}

Autism is a neurodevelopmental disorder characterized by three core diagnostic features: social deficits, communication impairments, and repetitive or stereotyped behaviors. Associated autistic characteristics such as sensory processing impairments and deficits in motor coordination are highly prevalent, yet have received less attention from the research community. As scientists continue to study patterns of symptom manifestation and

\section{KARGER}

Fax +4161306 1234

E-Mail karger@karger.ch

www.karger.com
(C) 2012 S. Karger AG, Basel

0378-5866/12/0343-0258\$38.00/0

Accessible online at:

www.karger.com/dne
Stacey Reynolds

Department of Occupational Therapy

Virginia Commonwealth University

Box 980008 , Richmond, VA 23298 (USA)

Tel. +1 352273 6126, E-Mail reynoldsse3@vcu.edu 
the developmental course of the disorder, sensory and motor features may be particularly important to consider in both human and animal paradigms.

\section{Sensory and Motor Features of Autism Spectrum Disorders}

Atypical responses to sensory stimulation have been reported in approximately $70-90 \%$ of individuals with autism spectrum disorders (ASD) $[1,2]$. Behavioral manifestations of atypical sensory processing have been most commonly classified as overresponding (hypersensitivity) and underresponding (hyposensitivity) [3] with both patterns being identified in the ASD population [1,4]. Further, these patterns of over- or underresponding appear to be strongly associated with other autism-related behaviors and functional performance in this population.

Tactile overresponsivity in particular has been associated with rigid and inflexible behavior, repetitive verbalizations, and visual stereotypies [5]. Overresponsivity in or across other sensory systems (e.g. visual and auditory) have also been found to predict high levels of stereotypies, compulsions, and rituals/sameness behaviors in children with autism, suggesting that overresponsivity and repetitive behaviors may share a common underlying neurobiology [6]. Similarly, Liss et al. [7] found that overresponsive children with ASD tended to have high overfocusing scores and high rates of perseverative behavior. These authors suggest that overresponsivity and repetitive behaviors may both be related to deficits in arousal regulation (overarousal) which may lead to overselective attention to sensory stimuli, perseverative preoccupations and repetitive movements. While the arousal theory has not been fully explored, sensory overresponsivity has been strongly associated with anxiety in children and adolescents with Asperger's syndrome [8], adults with autism [9], and in children with other neurodevelopmental disorders [10]. Elevated sympathetic arousal (electrodermal reactivity) in response to normal levels of sensory stimulation has also been shown to predict sleep deficits in children with autism, and behavioral patterns of overresponding have been strongly correlated with sleep problems in this population [11].

Whereas sensory underresponsivity has been commonly reported in ASD [12], it has been less well studied than overresponsivity. Underresponsive behaviors demonstrated by children with autism include not responding to their name being called, lacking attention to novel objects, ignoring loud sounds, and not responding to touch/ pain stimuli [1]. Patterns of sensory underresponsivity have been associated with impaired academic performance, poor attention to cognitive tasks and social skill deficits in children with ASD $[8,13]$. Liss et al. [7] found underresponsivity clustered with low adaptive functioning in children with autism, and suggested that underresponsivity may be related to low intellectual functioning in this population. Interestingly, academic performance and social interactions are areas that can be affected by depression [14]. In children and adolescents with ASD, underresponsiveness has been correlated with depressive symptoms, with the strength of the relationship between underresponsivity and depression increasing with age [8].

Similar to sensory processing impairments, motor impairments are highly pronounced in individuals with ASD, with multiple studies indicating that $100 \%$ of their sample population show impairments in at least one area of motor development [15-17]. Gross motor clumsiness and impairments in gait and balance have been commonly reported in both children and adults with ASD [18]. In addition to a delayed onset of walking, toddlers with autism have also been shown to lack a mature heel-toe pattern and have a more waddling gait compared to agematched controls [19]. These delays may be related to the high prevalence of hypotonia in ASD, which is present in approximately $50 \%$ of children with the disorder [20]. Fine motor deficits and impairments in upper limb coordination have also been commonly reported in the ASD population. Gernsbacher et al. [21] showed that in the first 2 years of life, fine motor skills such as pointing, clapping, reaching and constructional play were delayed in children later diagnosed with ASD. Older children and adolescents with autism have been shown to have difficulty with modulation of grip and force and with accuracy in reach-tograsp movements that are needed for tasks such as shoe tying and buttoning $[22,23]$. Though a fair degree of variability in performance has been reported, gross and fine motor coordination problems have been associated with reduced performance in daily life skills, play (e.g. running, throwing, jumping) and academic tasks such as handwriting in children with ASD, making these important behaviors to consider for this population $[24,25]$.

Interestingly, atypical sensory and motor features have been found to be salient early markers for ASD, identifiable as early as 4 months of age $[26,27]$. While the cause of atypical sensory and motor features in autism is not known, their manifestation early in life suggests that exploration of factors inducing neurological changes during early brain development is warranted.

\section{Teratogenic Effects of Valproate}

Exposure of the developing brain to teratogens is known to produce a myriad of symptoms and disorders 
that influence sensory and motor function. Valproate use during pregnancy (used by mothers as an antiepileptic, mood-stabilizing drug or migraine medication) has been associated with a higher prevalence of autism and autistic-linked behaviors in offspring $[28,29]$. Whereas autism prevalence in the typical population has been estimated around 1\% [30], Rasalam et al. [28] found that $8.9 \%$ of children exposed to valproate met the criteria for either autistic disorder or Asperger's syndrome; this suggests that exposure to valproate leads to approximately a 10 fold increase in the risk for developing an ASD. While sensory and motor behaviors in children exposed to valproate have not been fully characterized, case study reports lend insight into features that may be of particular relevance to this population. Williams and Hersh [31] described a 5.5-year-old boy exposed to valproate in utero and later diagnosed with autism. In addition to meeting core diagnostic criteria for autism, the child presented with muscular hypotonia, awkward gait, hyperreflexia, and was reported to cover his ears in response to hearing certain sounds. He also had insistence on routines connected with bathing and eating; features common in children with sensory overresponsivity. In a larger case report, Williams et al. [32] presented 5 children with both fetal valproate exposure and autism. In each of these cases, children presented with some form of motor impairment including decreased muscle tone, gross and fine motor incoordination, and atypical gait; sensory responsivity was not described in this group.

The strong association between valproate exposure in utero and the development of autism led Rodier et al. [33] to explore the effects of prenatal valproate treatment in rats. Since this publication, multiple studies have been published using pre- or postnatal valproate treatment to elicit neurological and behavioral features of autism in rodent models. The use of this valproate rodent model has potential utility for understanding the development and neurobiological basis of sensory and motor features seen in ASD.

\section{The Valproate Model of Teratogenicity in Rodents}

A single prenatal injection of valproate on embryonic day 12.5 (corresponding to the human 1st trimester following neural tube closure) has been shown most consistently to elicit autistic-like features such as repetitive behaviors and decreased social interaction in rodents [34]. Neurological features observed in rats treated with valproate on embryonic day 12.5 are similar to those seen in postmortem ASD human brains; these features include loss of cerebellar neurons [35] and altered dendritic arbo- rization in pyramidal cells suggestive of impaired pruning [36]. These valproate-exposed rats also show signs of tactile hypersensitivity during prepubertal adolescence on postnatal days (PND) 30-50, and impaired auditory sensory gating during adolescence and adulthood (PND90-120) [37, 38]. Impairments in sensory gating have been proposed to lead to sensory overload and strong reactions to environmental stimuli [37].

Evaluation of motor skills in this model is limited. Schneider and Przewłocki [38] found impaired swimming performance in prenatally valproate-exposed rats on PND8 and PND12; however, no delays were noted on PND10 or PND11. Wagner et al. [39] found that mice prenatally exposed to valproate had impaired righting reactions in the early juvenile stage but found no differences in vestibular function (negative geotaxis test) or motor development. Tests of fine motor function have not been assessed in this model.

Valproate has also been administered to rodents during the early postnatal period (PND0-14). Since rodents are born in an altricial state, the status of their developing neurological sensory systems roughly correspond with features associated with human brain development in the third trimester. For example, in the rodent auditory system, it has been shown that the cochlea matures and hearing onset occurs around PND11, and that bone conduction-related events can be measured as early as PND7 [40]. In humans, auditory responses can be evoked in utero as early as the 27th prenatal week, around the beginning of the third trimester [41, 42]. Further, general patterns of brain development, such as the brain growth spurt that occurs near the end of the third trimester in humans, occurs between PND1 and PND10 in rats [43, 44], supporting the notion that brain development in the final human trimester corresponds roughly to the first 1-2 weeks of rodent postnatal development $[45,46]$.

During this early rodent postnatal period, there is also a high degree of synaptogenesis and refinement of neurological connections, which is dependent on a balance between cellular excitation and inhibition [47]. Since valproate enhances inhibitory GABAergic activity [48, 49], it has the potential to disrupt brain development during this period. Similar to prenatal injections, postnatal valproate injections in rats have been shown to elicit autistic-like behaviors. Chomiak et al. [50] administered single doses of valproate $(150 \mathrm{mg} / \mathrm{kg})$ to rat pups for a maximum of 2 weeks starting at PND6; these rats showed a significant reduction in social play compared to litter-matched controls. Further, the postnatally valproate-treated rats showed an enlarged temporal association cortex and a temporar- 
ily accelerated pattern of neuronal development in the temporal lobe; these findings correspond to research indicating enlargement of temporal lobe regions in individuals with autism $[51,52]$. In mice, postnatal injection of valproate has been shown to impair vestibular function and midair righting reactions [39]. To our knowledge, no tests of sensory responsivity or skilled motor coordination have been conducted in the rodent postnatal valproate model. The purpose of this study, therefore, was to characterize sensory responsivity, sensory gating, and skilled motor performance in rats postnatally treated with valproate.

\section{Methods}

\section{Animals}

Thirty-four Long-Evans rats (24 male, 10 female) were bred in our lab using 4 experimentally naïve females. On PND3, 4 litters were cross-fostered so there were 8-9 pups per litter. The same day, the gender of each animal was established and each pup was randomly assigned to either the valproate or control group. To the best of our ability, each group had the same number of males (11 control, 13 valproate-treated) and females ( 5 control, 5 valproatetreated), and the same number of pups from each litter. Every day from PND6 to PND12, the offspring received an intraperitoneal injection of saline (control) or sodium valproate dissolved in $0.9 \%$ saline at $150 \mathrm{mg} / \mathrm{kg} /$ day [50]. The weight of the pups was monitored daily. Eye opening was recorded on PND13-16 and scored as either $0=$ both eyes closed, $1=$ one eye open, or $2=$ both eyes open. Pups were weaned on PND23 and pair-housed with animals matched by group and gender.

\section{Measures}

Sensory Responsivity and Gating

Sensory testing was conducted for each rat $(\mathrm{n}=34)$ on PND23 (juvenile stage, prior to weaning) and PND45 (adolescence) during the first $5 \mathrm{~h}$ of the light part of the daily light cycle. Auditory startle responses, tactile startle responses, and auditory sensory gating were measured using SR-LAB equipment (San Diego Instruments, San Diego, Calif., USA). The background sound level in the chamber was $70 \mathrm{~dB}$. Prior to the testing, each rat was acclimated to the test chamber for $5 \mathrm{~min}$. Each rat was then exposed to 20 consecutive trials of the auditory startle stimuli which were bursts of white noise $(10 \mathrm{kHz}, 120 \mathrm{~dB} / 40 \mathrm{~ms})$ presented at an average intertrial interval of $10 \mathrm{~s}$ (variable 5- to 15 -second range). At the end of the 20 trials, a no-stimulus trial was presented. The auditory startle session was followed by a 2-min break with background level sound $(70 \mathrm{~dB})$ only. Next, each rat was exposed to 20 consecutive trials of an auditory prepulse $(80 \mathrm{~dB} / 20 \mathrm{~ms})$ paired with the startle stimulus $(120 \mathrm{~dB} / 40 \mathrm{~ms})$. Frequency for the prepulse and stimulus was set at $10 \mathrm{kHz}$ and there was a $100-\mathrm{ms}$ interval between the prepulse and the stimulus. Each rat was exposed to 20 trials followed by a no-stimulus trial. The average intertrial interval was $10 \mathrm{~s}$. Following another 2-min break, each rat was exposed to 20 consecutive trials of the tactile startle stimulus which was a gentle air puff (psi = 20; lasting approx. $40 \mathrm{~ms}$ ) delivered to the mid-dorsal surface. Again, the intertrial interval was $10 \mathrm{~s}$ and the 20 trials were followed by a single no-stimulus trial. The primary variable of interest for each session was the peak response magnitude which was defined as the highest voltage during the response window.

\section{Sunflower Seed Eating Task}

Grasp and bilateral manual coordination was assessed using a sunflower seed eating task [53] on PND49. During the week prior to testing, all rats were exposed to sunflower seeds in their home cages ( 5 days of exposure, 3 seeds each time) in order to overcome neophobic responses and establish skill in handling [54]. Each rat was then acclimated to a clear plastic arena $(14 \times 11 \times 11$ in $)$ for 5 min 1 day prior to testing. Each rat was partially food restricted (8-10 g/day/rat) for 1 night prior to testing to increase motivation for task performance. On the morning of the test, 3 sunflower seeds were positioned in the front right corner of the testing chamber. The time needed to open all 3 seeds, as well as the number of pieces of shell produced, was measured. All testing was done within the first $4 \mathrm{~h}$ of the light part of the daily light cycle in a dimly illuminated room.

\section{Vermicelli Handling Test}

The vermicelli handling test has been used as a measure of forepaw dexterity in rodent models of stroke and neurodegenerative disease $[54,55]$. We chose this task to look at fine motor dexterity, reaching accuracy, postural control, and motor planning in the valproate- and vehicle-treated rats. During the week prior to testing, all rats were exposed to 3 -in strands of Müller's Brand vermicelli in their home cage (5 days of exposure, 3 strands each time) [54]. For 2 nights prior to testing, the rats were partially food restricted $(8-10 \mathrm{~g} / \mathrm{day} / \mathrm{rat})$ to encourage task performance. On PND50, each rat was placed individually into a clear observation cage (same as above). Three vermicelli strands were placed one at a time in the observation cage and the rats' eating behavior was recorded. A digital video camera was mounted on a tripod, which was repositioned during the test session so as to best record the rat's paw movements and posture during eating. All testing occurred in a dimly lit room during the first $5 \mathrm{~h}$ of the light part of the daily light cycle. After all testing was completed, the video recordings were reviewed for quality. Trials were removed if less than $90 \%$ of the recorded eating session showed a clear view of the paws/digits, head and body posture. Eight trials did not meet these criteria and therefore a total of 94 trials were included for analysis.

Videos were scored by personnel blinded to the experimental conditions. Interobserver reliability for all coded behaviors was greater than $80 \%$ with an average agreement rate of $89.9 \pm 6.4 \%$. During coding the videos were played at $6 \%$ normal speed. The primary variable of interest was the total number of paw adjustments per trial. As defined by other groups, an adjustment was scored each time there was a visible release of the pasta (not a drop) or a reformation of the digits holding the pasta via motor patterns of flexion/extension, or abduction/adduction [55].

A code sheet was developed for specific and relevant atypical sensorimotor behaviors based on an initial blinded review of 18 pasta trials, 9 trials randomly selected from each experimental group. Behaviors included on the code sheet were number of drops, failure to contact reaches, angling with head tilt, abnormal posture, use of a unilateral paw technique, and twirling of the pasta. Specific descriptions of the first 4 behaviors are defined elsewhere $[54,55]$. Unilateral contact was defined as any time the 

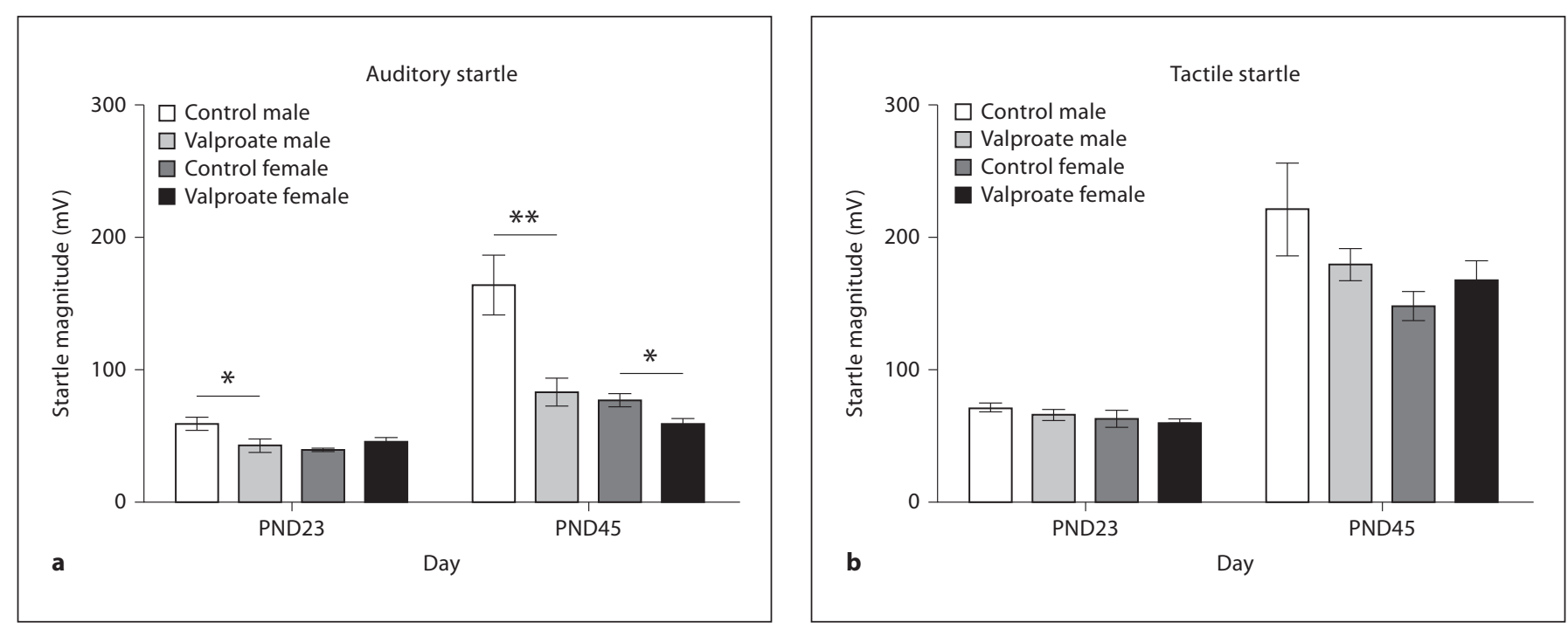

Fig. 1. Auditory (a) and tactile (b) startle response magnitude data for male and female rats in the control and valproate-treated groups on PND23 and PND45 $\left({ }^{*} \mathrm{p}<0.05 ;{ }^{* *} \mathrm{p}<0.01\right)$.

rat held the pasta in one paw for $5 \mathrm{~s}$ or more during eating without visible contact with the other paw. This was distinct from a 'failure to contact' code which was indicated each time the rat reached for the pasta but failed to make contact with its target. Twirling was defined as any time the pasta was rotated $180^{\circ}$ during positioning of the pasta for eating. This was seen as a potential indicator of impaired motor planning. The total time the rat spent actively eating (biting, chewing) the 3 pasta strands was recorded. All rats completed the task by consuming all 3 pasta pieces.

\section{Statistical Analysis}

For all analyses, an $\alpha \leq 0.05$ significance level was considered to be significant. The assumption of normality was assessed for all outcome variables and when the assumption was rejected, the appropriate nonparametric tests were utilized. Statistical analyses were conducted using PSAW Statistical Package 18.0. When examining group differences for multiple dependent variables, MANOVA models were used. A repeated-measures ANOVA was used for analysis of weight data which were taken over several days during early development. For sensory and motor variables, all the rats were initially analyzed in one model, followed by a separate analysis for males and females.

\section{Results}

\section{Health and Development}

All rats gained weight from approximately $14 \mathrm{~g}$ on PND6 (14.4 $\pm 1.2 \mathrm{~g})$ up to approximately $60 \mathrm{~g}$ on PND23 $(60.4 \pm 4.8 \mathrm{~g})$. A two-factor repeated-measures ANOVA was used to analyze body weight between control and val- proate-treated groups from PND6 (pretreatment) to PND23 (weaning). The analysis revealed a significant increase in weight over time $[\mathrm{F}(17,544)=2,130.89$; $\mathrm{p}<$ $0.0001]$. There was no significant time $\times$ group interaction $[\mathrm{F}(17,544)=1.38 ; \mathrm{p}=0.218]$.

There were also no significant differences found between groups for eye opening from PND13 to PND16. By PND15, $81 \%$ of the controls and $78 \%$ of the valproatetreated rats had their eyes open. All pups had both eyes open by PND16.

\section{Startle Responsivity}

Valproate-treated rats exhibited significantly smaller auditory startle responses compared to responses of control rats $[\mathrm{F}(1,33)=4.72 ; \mathrm{p}<0.05]$. These differences were present in male rats on $\operatorname{PND} 23[\mathrm{~F}(1,23)=5.36 ; \mathrm{p}<0.05]$ and PND45 $[\mathrm{F}(1,23)=11.65 ; \mathrm{p}<0.01]$. Female rats treated with valproate showed significantly smaller responses on PND45 [F $(1,9)=8.03 ; \mathrm{p}<0.05]$ but not on PND23 [F $(1$, $9)=1.62 ; \mathrm{p}=0.240]$. Tactile startle response magnitude did not differ significantly between groups $[\mathrm{F}(1,33)=$ 0.689; $\mathrm{p}=0.509$ ] (fig. 1).

\section{Sensorimotor Gating}

In the control group, the startle response after a prepulse was inhibited by $47 \%$ on PND23 and by $57 \%$ on PND45. In the valproate-treated group, the percent change was less apparent, with only a $36 \%$ reduction on 


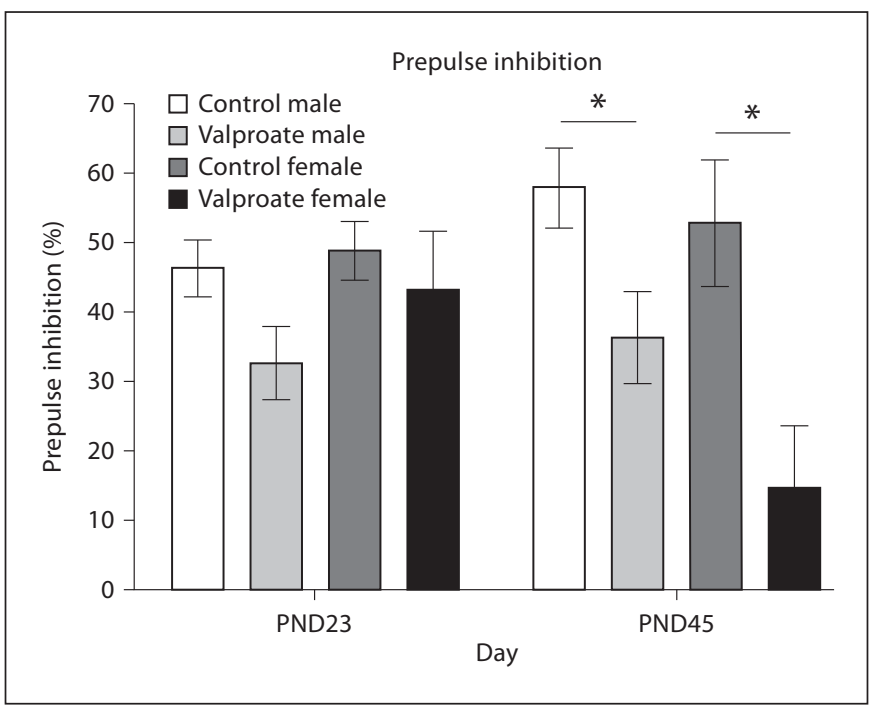

Fig. 2. Acoustic prepulse inhibition in male and female rats in the control and valproate-treated groups on PND23 and PND45 $\left({ }^{*} \mathrm{p}<0.05\right)$.

PND23 and a 30\% change on PND45. Group differences in prepulse inhibition were significant overall $[\mathrm{F}(1,33)=$ 8.68; $\mathrm{p}<0.01]$ and when examined separately on PND23 $[\mathrm{F}(1,33)=4.31 ; \mathrm{p}<0.05]$ and $\operatorname{PND} 45[\mathrm{~F}(1,33)=11.69$; $\mathrm{p} \leq 0.01]$. This trend remained when males were examined separately on PND45 $[\mathrm{F}(1,23)=5.76 ; \mathrm{p}<0.05]$ and approached significance on $\operatorname{PND} 23[\mathrm{~F}(1,23)=3.98 ; \mathrm{p}=$ 0.059 ]. In females, group differences in percent change were not seen on PND23 [F(1,9) = 0.360; $\mathrm{p}=0.565]$, but were found to be significant on $\operatorname{PND} 45[\mathrm{~F}(1,9)=8.84$; $\mathrm{p}<0.05]$ with valproate-treated females showing very little change in response magnitude when presented with a prepulse stimulus (fig. 2).

\section{Motor Performance}

The sunflower seed eating task was completed significantly faster by the control group compared to the valproate-treated group $[\mathrm{F}(1,33)=4.19 ; \mathrm{p}<0.05]$, but no differences were found in the number of shell pieces left after task completion, with the group means being nearly identical $[F(1,33)=0 ; p=1.00]$. When group differences between males and females were examined separately, no significant differences emerged for time or number of shell pieces.

During the vermicelli handling test, valproate-treated rats made significantly more paw adjustments $[\mathrm{F}(1,30)=$ $11.85 ; \mathrm{p}<0.01]$ and dropped the pasta significantly more often $[\mathrm{F}(1,30)=15.82, \mathrm{p}<0.001]$ than the control rats did.
These findings remained significant when males $[\mathrm{F}(1$, $20)=5.01 ; \mathrm{p}<0.05]$ and females $[\mathrm{F}(1,9)=7.00 ; \mathrm{p}<0.05]$ were examined separately. Valproate-treated rats also engaged in more atypical sensorimotor behaviors. Due to the nonnormal distribution of the majority of the count variables, we used a Mann-Whitney U test (1-tailed significance) to examine group differences. Based on this analysis, valproate-treated rats were found to use a unilateral technique significantly more often than control rats $(\mathrm{p}<0.001)$ and had more observed twirls $(\mathrm{p}<0.05)$, failure to contact reaches $(\mathrm{p}<0.05)$ and atypical postures $(\mathrm{p}<0.05)$ than the control group. When males were examined separately, use of the unilateral technique, twirls, and failure to contact reaches continued to be significantly different between the control and valproate-treated groups $(\mathrm{p}<0.01$ to $\mathrm{p}<0.05)$. For female rats, only use of a unilateral technique significantly differed between the groups ( $\mathrm{p}<0.05)$ (fig. 3 ).

A time score was recorded for each vermicelli trial (3 trials per subject). When all 3 time points were entered into a MANOVA model, the model was not found to be significant $[F(1,30)=1.78 ; p=0.174]$. However, when the trials were examined separately, the third trial was found to be significantly different between groups $[\mathrm{F}(1,30)=$ 5.38; $\mathrm{p} \leq 0.05$ ] with the valproate-treated rats taking significantly longer to complete the final trial. No differences were found between groups when males and females were examined separately.

Based upon visual examination of the vermicelli time trial data (fig. 4), there appeared to be a learning effect, with control rats (and not valproate-treated rats) showing improved speed with each trial. A repeated-measures ANOVA was therefore used to examine the effects of time and group $\times$ time interaction. While there was a significant effect of time $[\mathrm{F}(2,58)=4.77 ; \mathrm{p}<0.05]$, no time $\times$ group interaction was found $[\mathrm{F}(2,58)=0.803 ; \mathrm{p}=0.453]$.

\section{Discussion}

Here we have shown that early postnatal exposure to valproate leads to altered sensory responsivity, sensory gating, and motor performance in rats. Postnatally valproate-treated rats were underresponsive to auditory stimuli and showed deficits in auditory sensory gating. Sensory underresponsivity has been identified as the more prevalent form of sensory dysfunction in ASD, and it is the sensory characteristic that best distinguishes children with ASD from children with other neurodevelopmental disorders $[1,12]$. Further, deficits in prepulse 

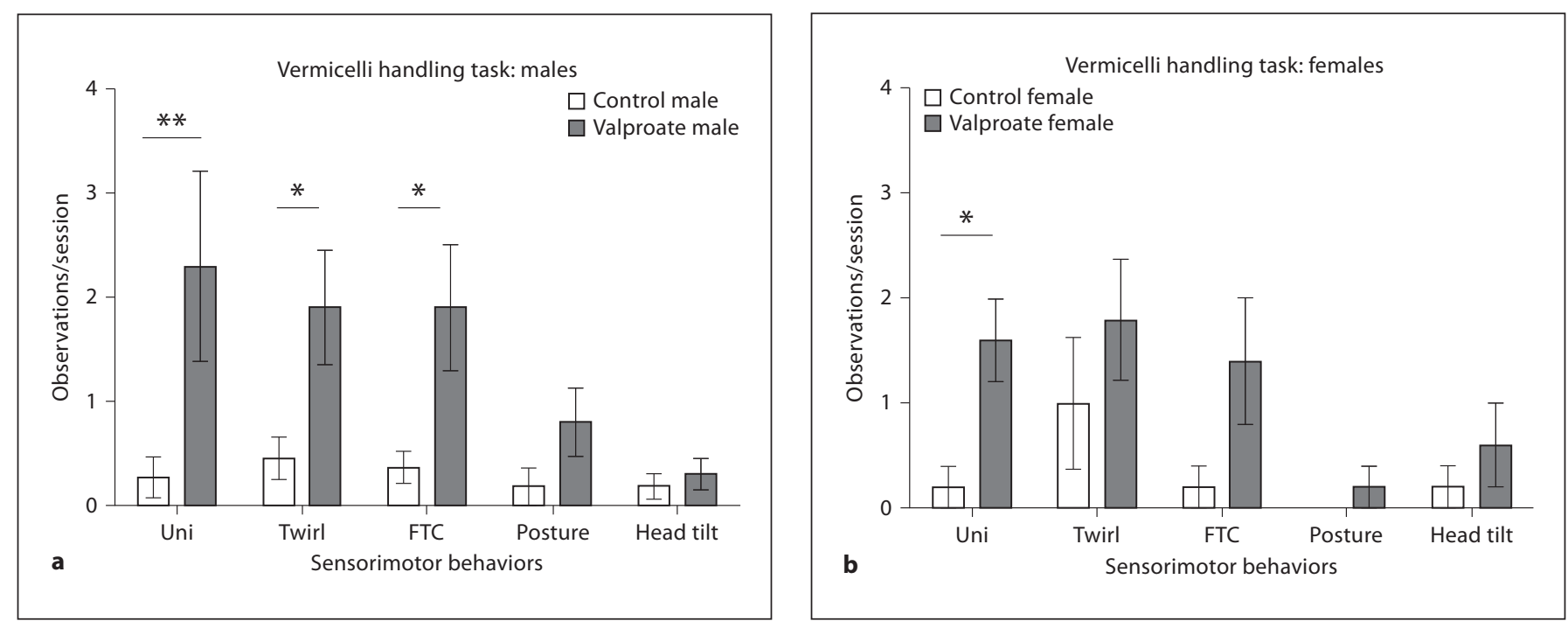

Fig. 3. Sensorimotor behaviors observed in male and female rats in the control and valproate-treated groups during the vermicelli handling task. Each session included 3 pasta trials $\left({ }^{*} \mathrm{p}<0.05 ;{ }^{*} \mathrm{p}<0.01\right)$. Uni $=$ Unilateral technique; Twirl $=$ rotation of the pasta $\geq 180^{\circ}$; FTC $=$ failure to contact reach; Posture $=$ observation of atypical posture; Head = angling of pasta with head tilt.

inhibition have been shown in adults with autism [56] and in children with autism and Fragile X syndrome [57]. Therefore, an animal model that exhibits auditory underresponsivity and sensory gating deficits may be particularly relevant for this diagnostic group.

Interestingly, prenatal valproate exposure has been shown to lead to sensory overresponsivity, particularly in the tactile domain [38] and this characteristic is redolent of another subset of autistic children who are overly sensitive to sensory stimuli. When considered alongside our data, this suggests that valproate exposure during salient pre- and postnatal periods of brain development in rodents may elicit the spectrum of over- and underresponsivity that is seen in individuals with ASD. No other animal model of autism has been shown to exhibit this range of behaviors. The data further suggest that the timing of teratogenic insult may invoke differing deficits in neural development and, therefore, a comparison of the biochemical impacts of the pre- and postnatal valproate models may help us to understand the nature of toxic insults that lead to specific behavioral abnormalities on the autism spectrum.

The finding that underresponsivity was only found in the auditory domain is relevant in the context of the rats' early postnatal brain development and the timing of the valproate injection. Sensitive periods for development of the auditory system occur over the first few weeks of post-

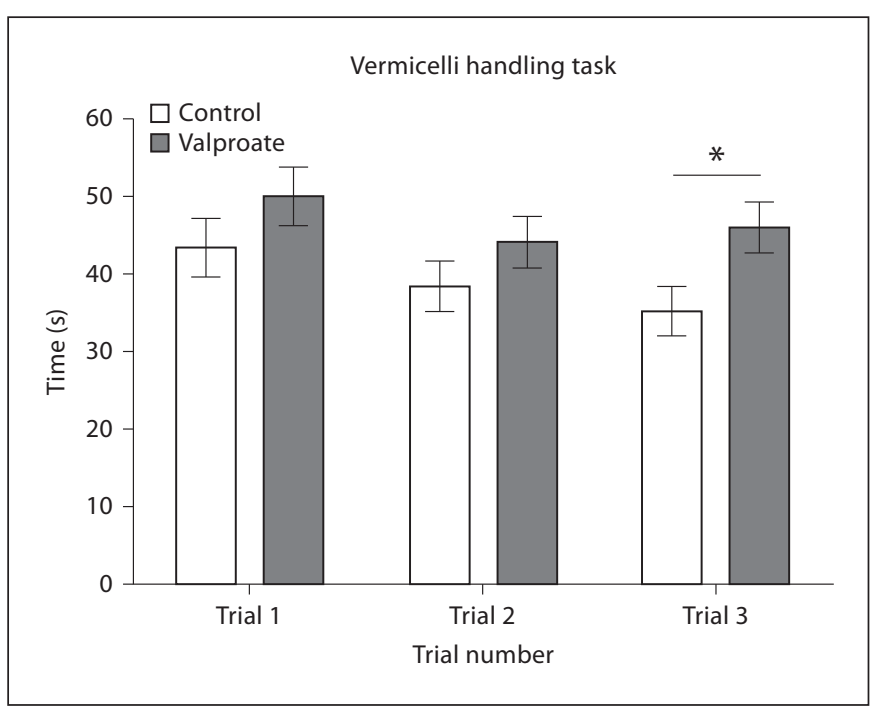

Fig. 4. Time required to complete each trial of the vermicelli handling task in control and valproate-treated rats $\left({ }^{*} \mathrm{p}<0.05\right)$.

natal development in rats. The injection time (PND6-12) corresponds to the sensitive period of development of the primary auditory cortex (A1) and the subcortical auditory system, which has been shown to range from PND4 to PND14 $[58,59]$ with refinement of receptive fields con- 
tinuing throughout the first month of life. In contrast, rapid cortical map plasticity occurs in layer 4 of the somatosensory cortex during the first week of postnatal rodent development [60] with distribution of thalamic afferents in the primary somatosensory cortex (S1) starting around PND0 and showing mature topographic orientation in relation to cortical barrels around PND4-7 [61, $62]$. While development of the somatosensory cortex continues to be refined over the first few weeks of life, particularly in layer $2 / 3[63,64]$, it is possible that PND0 to approximately PND5 would be the most salient for disruption of tactile responsivity. This is one possible explanation for why there were no significant differences in tactile responsivity between our control and valproatetreated rats, since our injections did not begin until PND6. Future studies are warranted which examine effects on tactile startle when injections are done in the first 5 days of postnatal development; this has yet to be examined in the rat or mouse model.

The effects of postnatal valproate exposure on sensory gating were also interesting to consider. Change scores (reported in percent change from auditory startle to auditory startle + prepulse) were significantly different between groups, with the valproate-treated rats showing a much smaller change in response magnitude. This may be due to the fact that their response to the auditory stimulus alone was significantly lower than that of controls and therefore the amount of gating required was much less; it is possible that initial startle responses in the valproate-treated rats were so low that a floor effect was seen when the prepulse stimulus was presented. This would suggest that in this particular animal model, the problem may be one of initial orientation rather than inhibition. Using electroencephalography, children with autism have been shown to have smaller amplitude responses to novel auditory stimuli, particularly in the P300 wave, compared to typical children and children with learning disorders [65, 66]. Whitehouse and Bishop [67] also reported that children with autism showed reduced orienting to novel tones presented in a sequence of speech sounds, suggesting potential links between auditory orienting responses and speech/language impairments in this population. While sensory gating deficits remain important to consider in the autism population, and in animal models of the disorder, additional testing paradigms are needed to understand and characterize these sensory processing characteristics more fully.

Gender-specific differences in sensory processing were also interesting to consider in this model. Female rats treated with valproate did not differ significantly

Sensory-Motor Characterization of

Post-Natal Valproate Model from control rats during the juvenile stage but were found to have significantly diminished auditory startle responses and altered sensorimotor gating during adolescence. It is possible that no significant differences on PND23 were found due to the small number of subjects in the female group. However, while effect sizes for both auditory startle and auditory gating were moderate in adolescence $\left(\mathrm{p} \eta^{2}=0.501, \mathrm{p} \eta^{2}=0.525\right)$, they were relatively small at the juvenile stage $\left(\mathrm{p} \eta^{2}=0.168, \mathrm{p} \eta^{2}=0.043\right)$. This suggests that even with a larger number, effects of valproate treatment would likely not be found in females on PND23 for these dependent variables. Human studies have shown that girls are often identified as autistic at a later age than boys [68] and this may suggest differences in the timing of symptom manifestation. To the best of our knowledge, no human studies have explored changes in sensory responsivity or sensory gating in children with ASD over time so it is unclear if this sensory processing shift in our adolescent rats translates to any human phenomena. Certainly, this is an area for further exploration.

Finally, group differences in motor performance were apparent between the valproate-treated and the control rats. Valproate-treated rats performed both the sunflower seed eating test and the final trial of the vermicelli handling test slower than control animals did. Therefore, while both groups were capable of performing the task (i.e. eating the item), the valproate-treated rats performed the task less efficiently. Since the valproate-treated rats required more paw adjustments and engaged in more atypical sensorimotor behaviors (e.g. twirling, use of unilateral technique), it appears that these rats had more difficulties in finer aspects of motor control and/or difficulty coordinating the functions of the forepaws bilaterally. Since optimal motor output is guided by accurate and efficient intake and processing of sensory input, impaired somatosensory processing is one explanation for the observed motor deficits. Despite the fact that we did not see differences in tactile startle responsivity between our valproate- and nonvalproate-treated groups, the fine motor/ motor-learning deficits observed in the motor tasks suggest that sensorimotor cortical development was affected by valproate treatment. Future studies may consider the use of discrimination-based tests for assessing somatosensory function in these animals, rather than a tactile startle paradigm which assesses the modulation of stimulus response. Regardless of the etiology, the observed deficits in motor behaviors such as forepaw dexterity and coordinated bilateral paw movements suggest that the postnatal valproate model does in fact mimic many of the atypical motor behaviors seen in children with ASD. 


\section{Conclusions}

Valproate use in humans during pregnancy has been shown to lead to a significantly higher incidence of autism and autism-related behaviors in offspring. Valproate treatment in rodents has, therefore, been suggested as a valid model for eliciting autistic-like behaviors in developmental neuroscience research. The goal of the present study was to characterize sensory responsivity, sensory gating, and skilled motor performance in rats postnatally treated with valproate. We conclude that this model does mimic many of the features seen in individuals with ASD including auditory underresponsivity which has not been documented in other animal models of autism. While results clearly indicate specific effects of valproate, future studies should consider the use of an untreated and unhandled control group to establish a developmen- tal time course of normal sensory and motor behavior. The use of pre- and postnatal valproate injections during sensitive periods of brain development may also prove useful for eliciting both under- and overresponsivity in specific sensory systems and provide a valid model for studying the range of sensory and motor deficits observed in individuals with ASD.

\section{Acknowledgements}

This project was funded by the National Center for Medical Rehabilitation Research and the National Institute of Neurological Disorders and Stroke (K12 HD055929) Rehabilitation Research Career Development Program. Thanks to Dr. Jeffrey Kleim and Nagheme Thomas for assistance and training in tests of rodent motor performance.

\section{References}

1 Baranek GT, David FJ, Poe MD, Stone WL, Watson LR: Sensory Experiences Questionnaire: discriminating sensory features in young children with autism, developmental delays, and typical development. J Child Psychol Psychiatry 2006;47:591-601.

-2 Lane AE, Young RL, Baker AE, Angley MT: Sensory processing subtypes in autism: association with adaptive behavior. J Autism Dev Disord 2010;40:112-122.

-3 Miller LJ, Anzalone ME, Lane SJ, Cermak SA, Osten ET: Concept evolution in sensory integration: a proposed nosology for diagnosis. Am J Occup Ther 2007;61:135-140.

4 Leekam SR, Nieto C, Libby SJ, Wing L, Gould $\mathrm{J}$ : Describing the sensory abnormalities of children and adults with autism. J Autism Dev Disord 2007;37:894-910.

5 Baranek GT, Foster LG, Berkson G: Tactile defensiveness and stereotyped behavior. Am J Occup Ther 1996;51:91-95.

-6 Boyd BA, Baranek GT, Sideris J, Poe MD Watson LR, Patten E, Miller H: Sensory features and repetitive behaviors in children with autism and developmental delays. Autism Res 2010;3:78-87.

7 Liss M, Saulnier C, Fein D, Kinsbourne M: Sensory and attention abnormalities in autistic spectrum disorders. Autism 2006; 10 : 155-172.

8 Pfeiffer B, Kinnealey M, Reed C, Herzberg G: Sensory modulation and affective disorders in children and adolescents with Asperger's disorder. Am J Occup Ther 2005;59:335345.

9 Gillott A, Standen PJ: Levels of anxiety and sources of stress in adults with autism. J Intellect Dis 2007;11:359-370.
10 Reynolds S, Lane SJ: Sensory over-responsivity and anxiety in children with ADHD. Am J Occup Ther 2009;63:433-440.

11 Reynolds S, Thacker L, Lane SJ: Sensory processing, physiological stress, and sleep behaviors in children with and without autism spectrum disorders. Occup Ther J Res DOI 10.3928/15394492-20110513-02.

12 Rogers SJ, Ozonoff S: Annotation: what do we know about sensory dysfunction in autism? A critical review of the empirical evidence. J Child Psychol Psychiatry 2005;46: 1255-1268.

13 Ashburner J, Ziviani J, Rodger S: Sensory processing and classroom emotional, behavioral, and educational outcomes in children with autism spectrum disorder. Am J Occup Ther 2008;62:564-573.

14 Field T, Diego M, Sanders C: Adolescent depression and risk factors. Adolescence 2001 36:491-498.

15 Ghaziuddin M, Butler E: Clumsiness in autism and Asperger syndrome: a further report. J Intellect Disabil Res 1998;42:43-48.

16 Green D, Baird G, Barnett AL, Henderson L, Huber J, Henderson SE: The severity and nature of motor impairment in Asperger's syndrome: a comparison with specific developmental disorder of motor function. J Child Psychol Psychiatry 2002;43:655-658.

17 Provost B, Lopez BR, Heimerl S: A comparison of motor delays in young children: autism spectrum disorder, developmental delay, and developmental concerns. J Autism Dev Disord 2007;37:321-328.

18 Fournier KA, Hass CJ, Naik SK, Lodha N, Cauraugh JH: Motor coordination in autism spectrum disorders: a synthesis and meta- analysis. J Autism Dev Disord 2010;40:12271240.

19 Esposito G, Venuti P: Analysis of toddlers' gait after six months of independent walking to identify autism: a preliminary study. Percept Mot Skills 2008;106:259-269.

20 Ming X, Brimacombe M, Wagner GC: Prevalence of motor impairment in autism spectrum disorders. Brain Dev 2007;29:565-570.

- 21 Gernsbacher MA, Sauer EA, Geye HM, Schweigert EK, Goldsmith HH: Infant and toddler oral- and manual-motor skills predict later speech fluency in autism. J Child Psychol Psychiatry 2008;49:43-50.

22 David FJ, Baranek GT, Giuliani CA, Mercer VS, Poe MD, Thorpe DE: A pilot study: coordination of precision grip in children and adolescents with high functioning autism. Pediatr Phys Ther 2009;21:205-211.

23 Mari M, Castiello U, Marks D, Marraffa C, Prior M: The reach-to-grasp movement in children with autism spectrum disorder. Philos Trans R Soc Lond B Biol Sci 2003;358: 393-403.

24 Kopp S, Beckung E, Gillberg C: Developmental coordination disorder and other motor control problems in girls with autism spectrum disorder and/or attention-deficit/ hyperactivity disorder. Res Dev Disabil 2010; 31:350-361.

25 Kushki A, Chau T, Anagnostou E: Handwriting difficulties in children with autism spectrum disorders: a scoping review. J Autism Dev Disord 2011;41:1706-1716.

26 Baranek GT: Autism during infancy: a retrospective video analysis of sensory-motor and social behaviors at 9-12 months of age. J Autism Dev Disord 1999;29:213-224. 
-27 Teitelbaum P, Teitelbaum O, Nye J, Fryman J, Maurer RG: Movement analysis in infancy may be useful for early diagnosis of autism. Proc Natl Acad Sci USA 1998;95:1398213987.

-28 Rasalam AD, Hailey H, Williams JH, Moore SJ, Turnpenny PD, Lloyd DJ, Dean JC: Characteristics of fetal anticonvulsant syndrome associated with autistic disorder. Dev Med Child Neurol 2005;47:551-555.

29 Moore SJ, Turnpenny P, Quinn A, Glover S, Lloyd DJ, Montgomery T, Dean JC: A clinical study of 57 children with fetal anticonvulsant syndromes. J Med Genet 2000;37:489497.

30 Fombonne E: Epidemiology of pervasive developmental disorders. Pediatr Res 2009;65: 591-598.

31 Williams PG, Hersh JH: A male with fetal valproate syndrome and autism. Dev Med Child Neurol 1997;39:362-634.

- 32 Williams G, King J, Cunningham M, Stephan M, Kerr B, Hersh JH: Fetal valproate syndrome and autism: additional evidence of an association. Dev Med Child Neurol 2001; 43:202-206.

- 33 Rodier PM, Ingram JL, Tisdale B, Nelson S, Romano J: Embryological origin for autism: developmental anomalies of the cranial nerve motor nuclei. J Comp Neurol 1996;370: 247-261.

- 34 Kim KC, Kim P, Go HS, Choi CS, Yang S, Cheong JH, Shin CY, Ko KH: The critical period of valproate exposure to induce autistic symptoms in Sprague-Dawley rats. Toxicol Lett 2011;201:137-142.

35 Ingram JL, Peckham SM, Tisdale B, Rodier PM: Prenatal exposure of rats to valproic acid reproduces the cerebellar anomalies associated with autism. Neurotoxicol Teratol 2000; 22:319-324.

- 36 Snow WM, Hartle K, Ivanco TL: Altered morphology of motor cortex neurons in the VPA rat model of autism. Dev Psychobiol 2008;50:633-639.

- 37 Markram K, Rinaldi T, La Mendola D, Sandi C, Markram H: Abnormal fear conditioning and amygdala processing in an animal model of autism. Neuropsychopharmacology 2008;33, 901-912.

- 38 Schneider T, Przewlocki R: Behavioral alterations in rats prenatally exposed to valproic acid: animal model of autism. Neuropsychopharmacology 2005;30:80-89.

- 39 Wagner GC, Reuhl KR, Cheh M, McRae P, Halladay AK: A new neurobehavioral model of autism in mice: pre- and postnatal exposure to sodium valproate. J Autism Dev Disord 2006;36:779-793.

40 Geal-Dor M, Freeman S, Li G, Sohmer H: Development of hearing in neonatal rats: air and bone conducted ABR thresholds. Hear Res 1993;69:236-242.
41 Froemke RC, Jones BJ: Development of auditory cortical synaptic receptive fields. Neurosci Biobehav Rev 2011;35:2105-2113.

42 Moore JK, Linthicum FH: The human auditory system: a timeline of development. Int J Audiol 2007;46:460-478.

43 Dobbing J: Under-nutrition and the developing brain. The relevance of animal models to the human problem. Am J Dis Child 1970; 120:411-415.

44 Dobbing J: The later development of the brain and its vulnerability; in Davis JA, Dobbing J (eds): Scientific Foundations of Paediatrics. Baltimore, University Park Press, 1981, pp 744-748.

45 Clancy B, Finlay BL, Darlington RB, Anand KJS: Extrapolating brain development from experimental species to humans. Neurotoxicology 2007;28:931-937.

46 Clancy B, Darlington RB, Finlay BL: Translating developmental time across mammalian species. Neuroscience 2001;105:7-17.

47 Pohl-Guimaraes F, Krahe TE, Medina AE: Early valproic acid exposure alters functional organization in the primary visual cortex. Exp Neurol 2011;228:138-148.

48 Loscher W: Basic pharmacology of valproate: a review after 35 years of clinical use for the treatment of epilepsy. CNS Drugs 2002;16: 669-694.

49 Gobbi G, Janiri L: Sodium- and magnesiumvalproate in vivo modulate glutamatergic and GABAergic synapses in the medial prefrontal cortex. Psychopharmacology 2006; 185:255-262.

50 Chomiak T, Karnik V, Block E, Hu B: Altering the trajectory of early postnatal cortical development can lead to structural and behavioural features of autism. BMC Neurosci 2010;11:1-10.

51 Bailey A, Luthert P, Dean A, Harding B, Janota I, Montgomery M, Rutter M, Lantos P: A clinicopathological study of autism. Brain 1998;121:889-905.

52 Hazlett HC, Poe M, Gerig G, Smith RG, Provenzale J, Ross A, Gilmore J, Piven J: Magnetic resonance imaging and head circumference study of brain size in autism: birth through age 2 years. Arch Gen Psychiatry 2005;62:1366-1376.

53 Wishaw IQ, Coles BLK: Varieties of paw and digit movement during spontaneous food handling in rats: postures, bimanual coordination, preferences, and the effect of forelimb cortex lesions. Behav Brain Res 1996;77: 135-148.

54 Tennant KA, Asay AL, Allred RP, Ozburn AR, Kleim JA, Jones TA: The vermicelli and capellini handling tests: simple quantitative measures of dexterous forepaw function in rats and mice. J Vis Exp 2010;41:pii2076.
5 Allred RP, Adkins DL, Woodlee M, Husbands LC, Maldonado MA, Kane JR, Schallert $\mathrm{T}$, Jones TA: The vermicelli handling test: a simple quantitative measure of dexterous forepaw function in rats. J Neurosci Methods 2008;170:229-244.

56 Perry W, Minassian A, Lopez B, Maron L, Lincoln A: Sensorimotor gating deficits in adults with autism. Biol Psychiatry 2007;61: 482-486.

57 Yuhas J, Cordeiro L, Tassone F, Ballinger E, Schneider A, Long JM, Ornitz EM, Hessl D: Brief report: sensorimotor gating in idiopathic autism and autism associated with fragile X syndrome. J Autism Dev Disord 2011;41:248-253.

58 de Villers-Sidani E, Simpson KL, Lu Y, Lin RCS, Merzenich MM: Manipulating critical period closure across different sectors of the primary auditory cortex. Nat Neurosci 2008; 11:957-965.

59 Fathke RL, Gabriele ML: Patterning of multiple layered projections to the auditory midbrain prior to experience. Hear Res 2009; 249:36-43.

60 Feldman DE, Brecht M: Map plasticity in the somatosensory cortex. Science 2005;310: 810-815.

61 Inan M, Crair MC: Development of cortical maps: perspectives from the barrel cortex. Neuroscientist 2007;13:49-61.

62 Schlaggar BL, O’Leary DDM: Early development of the somatotopic map and barrel patterning in rat somatosensory cortex. J Comp Neurol 1994;346:80-96.

63 Stern EA, Maravall M, Svoboda K: Rapid development and plasticity of layer $2 / 3$ maps in rat barrel cortex in vivo. Neuron 2001;31: 305-315.

64 Lendvai B, Stern E, Chen B, Svoboda K: Experience-dependent plasticity of dendritic spines in the developing rat barrel cortex in vivo. Nature 2000;404:876-881.

65 Courchesne E, Kilman BA, Galambos R, Lincoln AJ: Autism: processing of novel auditory information assessed by event-related brain potentials. Electroencephalogr Clin Neurophysiol 1984;59:238-248

-66 Kemner C, Verbaten MN, Cuperus JM, Camfferman G, van Engeland H: Auditory event-related brain potentials in autistic children and three different control groups. Biol Psychiatry 1995;38:150-165.

67 Whitehouse AJO, Bishop DVM: Do children with autism 'switch off' to speech sounds? An investigation using event-related potentials. Developmental Sci 2008;11:516-524.

68 Giarelli E, Wiggins LD, Rice CE, Levy SE, Kirby RS, Pinto-Martin J, Mandell D: Sex differences in the evaluation and diagnosis of autism spectrum disorders among children. Disabil Health J 2010;3:107-116. 